\title{
Numerical Investigation on Crack Propagation and Fatigue Life Estimation of Shield Lining under Train Vibration Load
}

\author{
Long-gang Tian $\mathbb{D}^{1},{ }^{1}$ Zi-ling Cheng $\mathbb{D}^{2},{ }^{2}$ and Zhi-qiang $\mathrm{Hu} \mathbb{i}^{1}$ \\ ${ }^{1}$ School of Civil Engineering, Southeast University, Nanjing 211189, China \\ ${ }^{2}$ Southeast University-Monash University Joint Graduate School, Suzhou 215123, China \\ Correspondence should be addressed to Long-gang Tian; lgtian@seu.edu.cn
}

Received 30 June 2021; Revised 16 July 2021; Accepted 22 July 2021; Published 29 July 2021

Academic Editor: Xuepeng Zhang

Copyright (C) 2021 Long-gang Tian et al. This is an open access article distributed under the Creative Commons Attribution License, which permits unrestricted use, distribution, and reproduction in any medium, provided the original work is properly cited.

\begin{abstract}
Dynamic loads such as the train vibration load usually act on the shield tunnel lining in the long term, which could make the initial flaws in shield segment propagate and gradually weaken the robustness of the tunnel structure. In this paper, a three-dimensional numerical model of shield tunnel lining structure with the initial defect is built to study its dynamic reaction and fatigue crack propagation under the train vibration load. Furthermore, the damage to intact shield segment caused by train vibration load is studied by employing the rain-flow counting method and the Miner damage theory, and a rational fatigue life estimation for the concrete shield tunnel lining is finally made. Results show that crack propagation is influenced by both the train speed and train axle, the higher the train speed, the longer the final crack, and train axle has a larger influence than train speed on the crack propagation in shield tunnel segment. The shield tunnel lining structure of Nanjing Metro Line 5 can meet the demand of working for a hundred years under the current working conditions.
\end{abstract}

\section{Introduction}

As one kind of the public transportation, subway has played a more and more important role in the contemporary society nowadays, especially in the modern metropolises. The main structure of the subway system is the so-called shield tunnel lining structure, which usually consists of plenty of concrete shield segments. The shield segments are manufactured in the factory and transported to the construction site in a long distance, and they are usually assembled one by one in situ; thus, some initial flaws such as cracks may come into being in these shield segments. Furthermore, the lining structure of the shield tunnel is under train vibration load day and night, making these flaws propagate ceaselessly. All of these produce a large threat to the shield tunnel system. Moreover, even if the shield tunnel lining is intact without any defect, it has a significant and realistic value to make a rational life estimation of the shield tunnel lining.

During the past several decades, numerous numerical and experimental research studies have been conducted on shield tunnel structures. The Railway Engineering Society of the United Kingdom [1] studied the vertical wheel-rail force of the train by both theoretical analysis and experiment in 1970s. Newton and Clark [2] compared the Timoshenko beam model with the Euler beam model and concluded that the predicted wheel-rail forces of the train using these two models are close to each other, while the Euler beam model is much simpler than the other one. Yang and Hung [3-5] proposed a simplified 2.5D finite element-infinite element coupling model, using finite element to simulate the near field and infinite element to simulate the far field, and obtained quite good results. Sheng et al. [6, 7] proposed a semispace numerical method for a circular tunnel based on the wavenumber finite and boundary element method. Degrande et al. [8] developed a finite element-boundary element coupling method to calculate subway vibration and proposed a highly efficient numerical model. Forrest and Hunt $[9,10]$ proposed a pipe-in-pipe model to study the train-induced ground vibration in underground tunnel, and the computational efficiency of this model is rather good. 
Seleznev et al. $[11,12]$ developed a method to study an elastic half-space containing a cylindrical tunnel. Gardien and Stuit [13] proposed a model consisting of three submodels to analyse the tunnel vibration induced by train and to reduce the numerical burden using finite element analysis. Other research studies on tunnel vibration included the application of Green's functions [14] and three-dimensional finite element simulations of long tunnels in half-space [15-17]. For the studies of practical projects in engineering, Lai et al. [18] conducted a study concerned with the assessment of the vibration induced by the passage of commuter trains running in a tunnel placed underground of the city of Rome, using both the numerical simulation and field monitoring. Huang et al. [19] studied the dynamic characteristics of the tunnel invert for high-speed railways. Connolly et al. [20] analysed 1500 records of ground vibration from 17 highspeed railway stations in Europe and found that the soil property was the main factor which had an influence on the ground vibration. Yi et al. [21] and Wei et al. [22] studied the dynamic reactions of Guangzhou Metro Line by both the indoor model tests and numerical simulations. Besides, a series of numerical simulations on damage and fatigue analysis of some representative structures in civil engineering have been conducted [23-27], and lots of useful results have been obtained for practical engineering.

The shield tunnel lining segment is usually precast with concrete in factories. Concrete is a kind of man-made material which is brittle and sometimes fragile. Lots of studies have been conducted on the fracture and fatigue properties of concrete in the past century [28-32]. Besides, Shah [33] acquired the fracture parameters for the concrete fracture model using the three-point bending test. Kazemi [34] proposed the process zone model and applied it to the fracture analysis of concrete structures. Karihaloo and Nallathambi [35] found that the fracture toughness of concrete was not determined by the shape or dimension of the specimen but by the size effect model with mixed variables. $\mathrm{Xu}$ et al. $[36,37]$ proposed the double- $K$ fracture criterion for concrete, which has been widely used for the fracture analysis of concrete structures since then. By employing the double- $K$ fracture criterion of concrete, Tian et al. $[38,39]$ conducted prototype load tests and threedimensional numerical simulations to investigate the fracture property and failure model of concrete shield segments.

In this paper, a three-dimensional numerical model of the shield tunnel lining structure based on Nanjing Metro Line 5 is built in ABAQUS to study the structure reaction and fatigue crack growth under train vibration load. Besides, damage to the shield segment induced by the train vibration load is also calculated by employing the Miner damage theory and $S-N$ fatigue law of concrete, and the fatigue life of the concrete shield lining is rationally estimated.

\section{Numerical Model and Train Vibration Load}

2.1. Numerical Model of the Shield Lining. The numerical model of the shield tunnel lining is built according to the real shield tunnel of Nanjing Metro Line 5 in China. Thickness of the segment is $350 \mathrm{~mm}$, and the inner diameter of the tunnel lining is $5500 \mathrm{~mm}$. The intact lining ring consists of six components, which include one sealing-roof segment, two adjacent segments, and three standard segments. The joints of the adjacent segments are connected by M30 bolts. The cross section of the tunnel lining ring is illustrated in Figure 1 , in which $A$ denotes the standard segment, $B$ denotes the adjacent segment, and $K$ denotes the sealing-roof segment. Due to the complexity of rebars in the concrete shield tunnel segments, they are not considered in the current numerical simulation.

The numerical models of the shield tunnel are built in FEM software ABAQUS, which are shown in Figures 2-4. Note that there are circumferential bolts and longitudinal bolts in the numerical model of the shield tunnel lining, as shown in Figure 4, and they are "tied" with the concrete in the numerical simulation.

Concrete grade of this tunnel segment is C50, and its material properties are listed in Table 1.

2.2. The Train Vibration Load. The train vibration load of the subway is a very complex variable which is influenced by many factors, such as the train axle, speed of the train, rail irregularity, and so on. The best way to obtain train vibration load is to conduct in situ monitoring, despite the fact that it usually costs plenty of human labour as well as economic burden. In this numerical simulation, the empirical formula recommended by the Railway Engineering Society of the United Kingdom is employed to calculate the train vibration [1], which is expressed as follows:

$$
F(t)=P_{0}+P_{1} \sin \left(\omega_{1} t\right)+P_{2} \sin \left(\omega_{2} t\right)+P_{3} \sin \left(\omega_{3} t\right)
$$

where $P_{0}$ denotes the static load of the wheel axel and $P_{1}, P_{2}, P_{3}$ denote three vibration loads with different frequencies.

The vibration loads can be expressed as follows:

$$
P_{i}=M_{0} a_{i} \omega_{i}^{2}, \quad i=1,2,3,
$$

where $M_{0}$ denotes the mass of the train, $a_{i}$ denotes the arch rise, and $\omega_{i}$ denotes the circular frequency of the vibration wave. The circular frequency is expressed as

$$
\omega_{i}=\frac{2 \pi v}{L_{i}}, \quad i=1,2,3,
$$

where $v$ denotes the speed of the train and $L_{i}$ denotes the wavelength.

The related parameters for the aforementioned formulas are listed in Table 2.

The axle for the train of Nanjing Metro Line 5 is $16 \mathrm{t}$, and the speed of the train for the numerical simulation is $80 \mathrm{~km} / \mathrm{h}$. The wavelength of the carriage smoothness is $10 \mathrm{~m}$, and the versine is $5 \mathrm{~mm}$. The wavelength for waveform wearning is $0.5 \mathrm{~m}$, and its versine is $0.005 \mathrm{~mm}$. The timehistory curve of the train vibration load is depicted in Figure 5. The aforementioned train vibration loads are applied at the position of wheel track at the bottom segment of the tunnel lining, as described by equation (1), and their time-history curve is illustrated in Figure 5. 


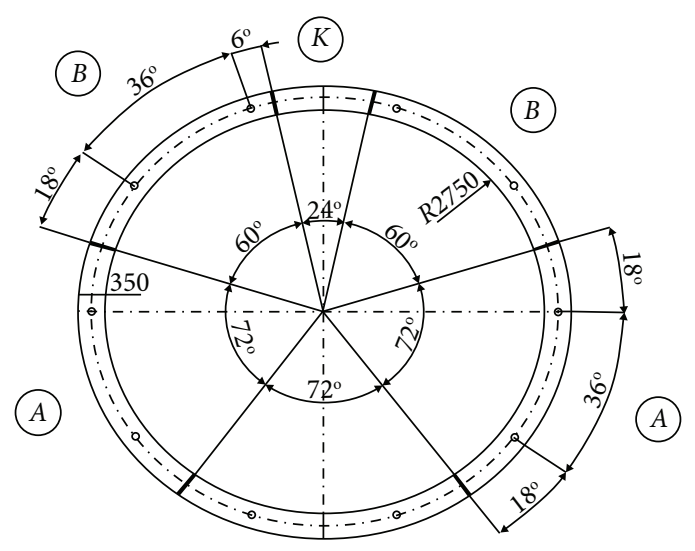

(A)

Figure 1: Cross section of the shield tunnel lining.

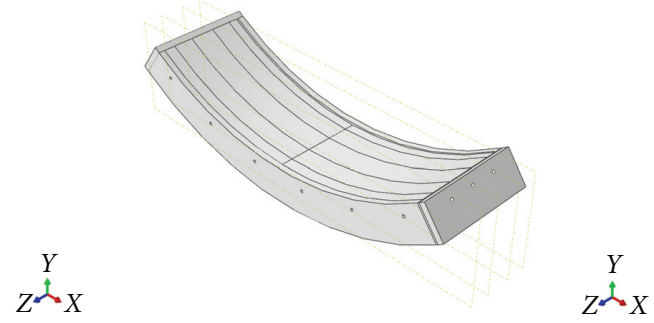

(a)

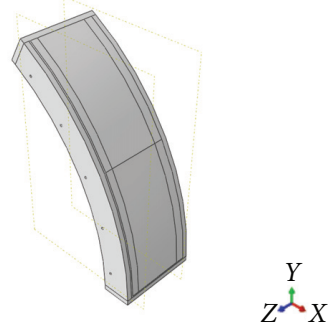

(b)

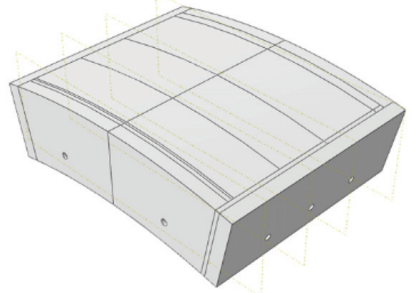

(c)

$$
Z^{Y} \stackrel{\leftrightarrow}{\circ}_{X}
$$

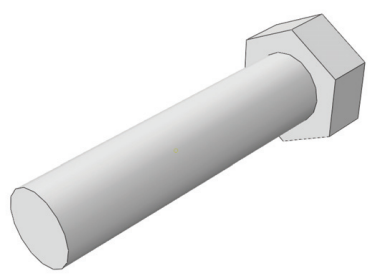

(d)

FIGURE 2: Numerical model of the shield tunnel lining. (a) The standard segment. (b) The adjacent segment. (c) The sealing-roof segment. (d) The bolt.

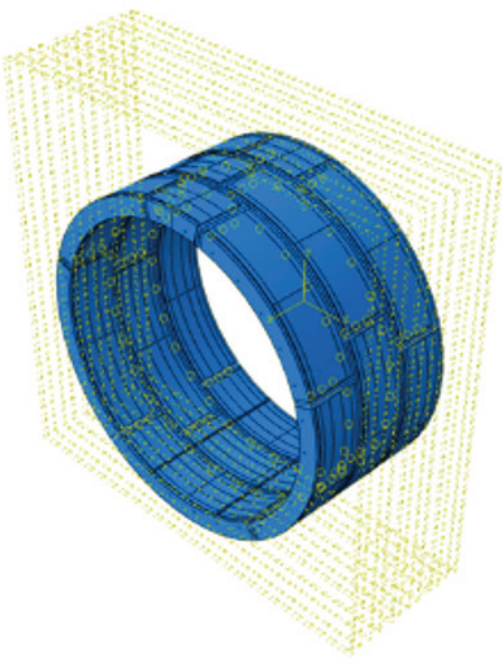

Figure 3: The overall numerical model of the shield tunnel lining ring. 


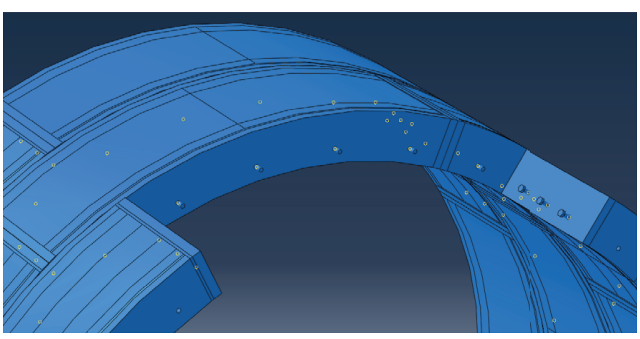

(a)

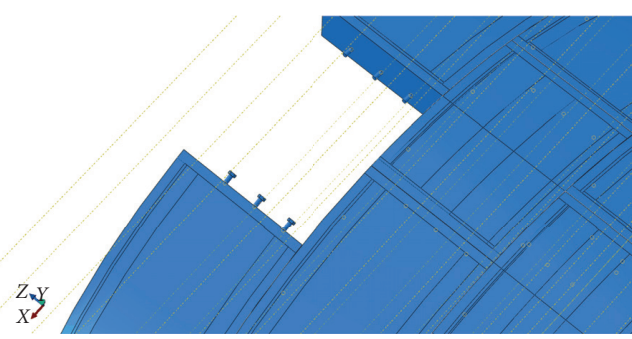

(b)

FIgURE 4: The magnified view of the bolts for the shield tunnel joints.

TABLE 1: Material properties of the shield tunnel lining.

\begin{tabular}{lccc}
\hline Material & $\begin{array}{c}\text { Elastic } \\
\text { modulus (MPa) }\end{array}$ & Poisson's ratio & Density $\left(\mathrm{kg} / \mathrm{m}^{3}\right)$ \\
\hline Concrete C50 & 34500 & 0.2 & 2500 \\
M30 bolt & 209000 & 0.269 & 7890 \\
\hline
\end{tabular}

TABle 2: Parameters for the train vibration load.

\begin{tabular}{lcc}
\hline Condition & $\begin{array}{c}\text { Wavelength } \\
(\mathrm{m})\end{array}$ & $\begin{array}{c}\text { Versine } \\
(\mathrm{mm})\end{array}$ \\
\hline \multirow{2}{*}{ Based on the carriage smoothness } & 50 & 16 \\
& 20 & 9 \\
\multirow{2}{*}{ Based on dynamic additional } & 10 & 5 \\
load & 5 & 2.5 \\
\multirow{2}{*}{ Waveform wearning } & 2 & 0.6 \\
& 1 & 0.1 \\
\hline
\end{tabular}

\section{Crack Propagation}

3.1. The Fatigue Criterion. Lots of fatigue laws have been proposed and applied for the fatigue analysis of various kinds of materials in engineering during the past several decades; among them, the Paris law [40] is the most widely used one due to its simplicity. The general form of Paris law is usually expressed as follows:

$$
\frac{\mathrm{d} a}{\mathrm{~d} N}=C(\Delta K)^{n},
$$

where $a$ denotes the crack length $(\mathrm{mm}) ; N$ denotes the fatigue load cycles; $(\mathrm{d} a / \mathrm{dN})$ denotes the crack increment during each load cycle; $\Delta K$ denotes the stress intensity factor range, with the unit of $\mathrm{Pa} \sqrt{\mathrm{m}}$; and $C$ and $n$ are constants related to the material properties.

The Paris fatigue law is often used for metals, but research studies on concrete [41] show that it could be applied to concrete material as well, with the following expression:

$$
\frac{\mathrm{d} a}{\mathrm{~d} N}=3.43 \times 10^{-3}(\Delta K)^{-17.393\left(a_{0} / D\right)+12.844},
$$

where $a_{0}$ denotes the initial crack depth and $D$ denotes thickness of the concrete specimen.

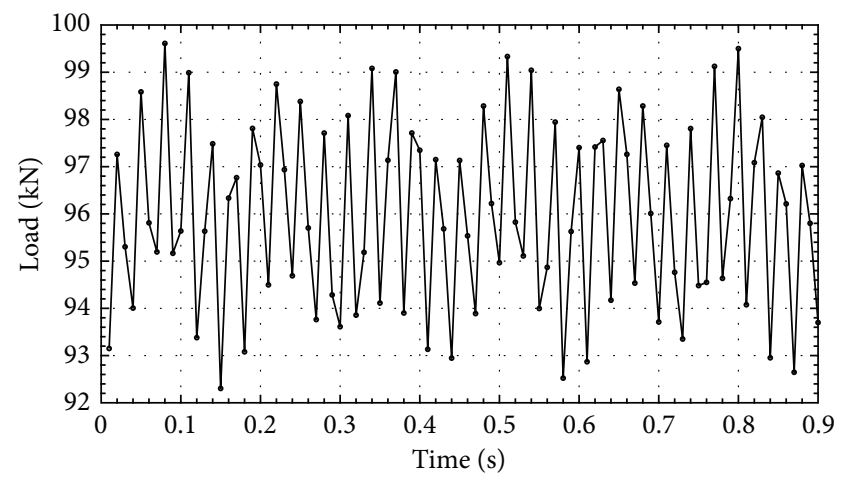

Figure 5: The time-history curve of the train vibration load.

As the stress intensity factor can depict the stress field near the crack tip, it is the most important variable for fracture and fatigue analysis of concrete structures. The double- $K$ fracture criterion [37] is employed in this study for crack propagation simulation of the concrete shield tunnel ling. For concrete $\mathrm{C} 50$, its measured initial fracture toughness is $0.714 \mathrm{MPa} \sqrt{\mathrm{m}}$, and the ultimate fracture toughness is $1.416 \mathrm{MPa} \sqrt{\mathrm{m}}$.

3.2. The Crack Propagation Path. In this section, the numerical simulation is conducted on the standard segment. The dimension for the initial crack is $300 \mathrm{~mm} \times 25 \mathrm{~mm}$, and the number of load cycles is set to $10^{8}$. The train axle weighs $16 \mathrm{t}$, and the standard speed of the train is $80 \mathrm{~km} / \mathrm{h}$.

The numerical model with an initial crack is shown in Figure 6, in which the area with red colour represents the initial crack. The final crack is shown in Figure 7 under the cyclic train vibration load. Since the initial crack is so small, only the segment which contains the crack is shown in Figures 6-9.

3.3. The Influence of Train Speed. The influence of train speed on the crack propagation is studied in this section. The dimension for the initial crack is $300 \mathrm{~mm} \times 25 \mathrm{~mm}$, and the number of load cycles is set to $10^{8}$. The train axle weighs $16 \mathrm{t}$, and the train speeds are set to four levels, which include $100 \mathrm{~km} / \mathrm{h}, 80 \mathrm{~km} / \mathrm{h}, 60 \mathrm{~km} / \mathrm{h}$, and $40 \mathrm{~km} / \mathrm{h}$. The final crack propagation path under four different train speeds is shown in Figure 8. 


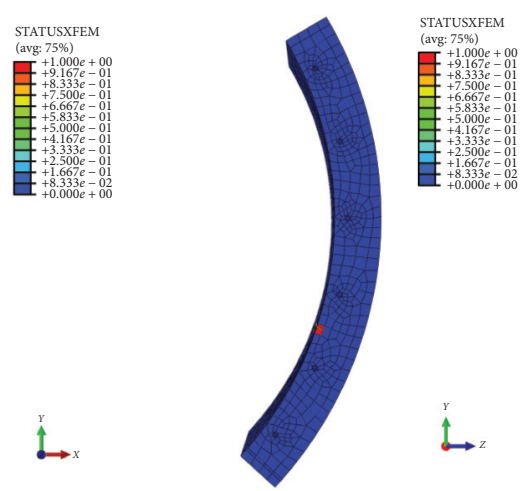

(a)

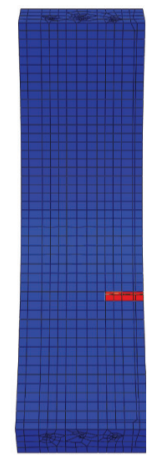

(b)

FIgURE 6: The initial crack in the shield tunnel segment.
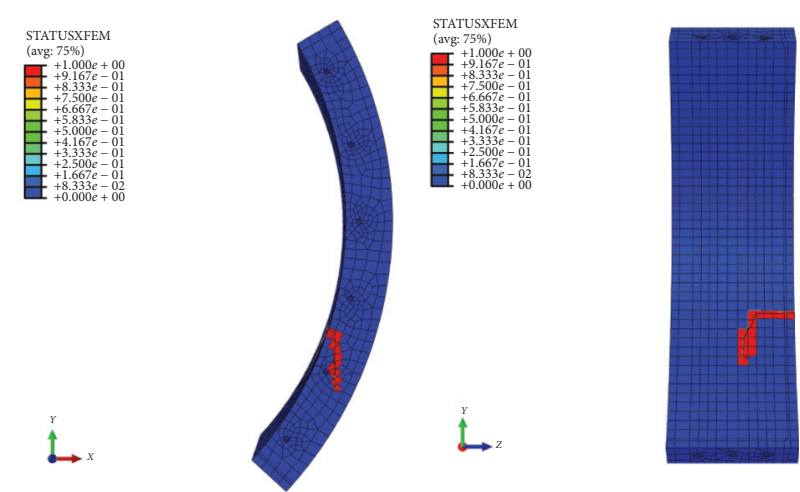

(a)

(b)

FIgUre 7: The final crack in the shield tunnel segment.

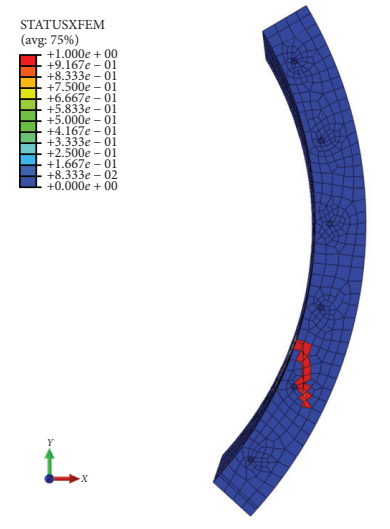

(a)

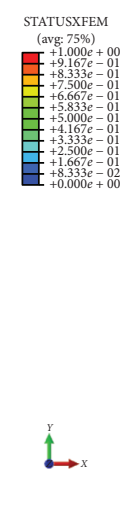

(b)

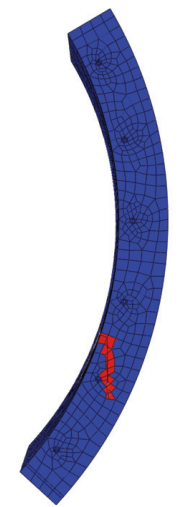

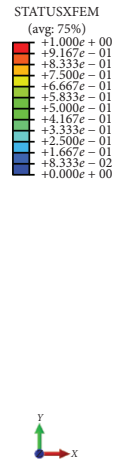

(c)

Figure 8: Continued. 


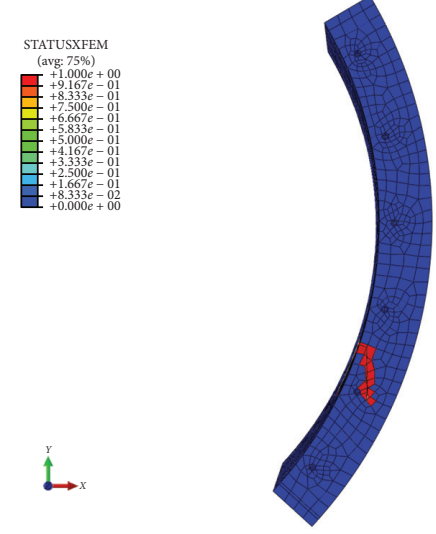

(d)

Figure 8: The final crack in the shield segment under different train speeds: (a) $100 \mathrm{~km} / \mathrm{h}$; (b) $80 \mathrm{~km} / \mathrm{h}$; (c) $60 \mathrm{~km} / \mathrm{h}$; (d) $40 \mathrm{~km} / \mathrm{h}$.

As shown in Figure 8, crack propagation shows the same path overall under different train speeds, while the final crack lengths are a little different. The higher the train speed, the longer the final crack.

3.4. The Influence of Train Axle. The influence of train axle on the crack propagation is studied in this section. Dimension of the initial crack and number of load cycles are the same as those in Section 3.3. The train speed is fixed at $80 \mathrm{~km} / \mathrm{h}$, and the train axles are set to four levels, which include $18 \mathrm{t}, 16 \mathrm{t}, 14 \mathrm{t}$, and $12 \mathrm{t}$. The final crack propagation path under four different train axles is shown in Figure 9.

As shown in Figure 9, crack propagation shows the same path overall under different train axles, while the final crack lengths are very different. The final crack under train axle of $18 \mathrm{t}$ is so long that it almost cuts through the shield segment, while the final crack under train axle of $12 \mathrm{t}$ is quite short and only develops to a local crack.

\section{Fatigue Life Estimation}

4.1. The Rain-Flow Counting Method. The rain-flow counting method [42] is widely used to deal with the time-history of load in engineering, which could account for the memory characteristics of the material. In the rain-flow counting method, the time-history of load is decomposed into several loading cycles which include the loading amplitude and loading mean value, in order to make a rational fatigue life estimation of the structure based on the fatigue law of the material.

Figure 10 shows a schematic diagram for the rain-flow counting method. The rain-flow persistently flows from top to bottom along the slope, until it encounters a larger peak value or the upper rain-flow. The fundamental principle of the rainflow counting method is illustrated by the following figure.

4.2. Miner Damage Theory and S-N Equation. The Miner damage theory assumes that if the structure is subjected to different cyclic stress $S_{i}$, the damage caused by cyclic loading
$S_{i}$ is $n_{i} / N_{i}$. Structure fatigue failure occurs when the cumulative damage of the structure under various stress levels reaches 1 . That is to say, to prevent the fatigue failure of the structure, the following equation must be satisfied:

$$
D_{\text {total }}=\sum_{i=1}^{k} D_{n_{i}, s_{i}}=\sum_{i=1}^{k} \frac{n_{i}}{N_{i}} \leq 1,
$$

where $D_{\text {Total }}$ is the total damage of the structure, $n_{i}$ is the applied times for the cyclic loading $S_{i}$, and $N_{i}$ is the life expectancy of the structure only subjected to cyclic loading $S_{i}$.

For the concrete shield tunnel lining with no initial flaws, it is a challenging subject to predict its crack initiation and make a rational life estimation. In this section, the steel reinforcements are assumed to be reliable in the long term, so the fatigue life of the shield tunnel structure is dominated by its concrete material. For its concrete with strength grade C50, the fatigue equation proposed by Guangyi Zhao is employed in this study, which is expressed as follows:

$$
S_{\max }=0.965-0.054 \log N \text {, }
$$

where $S_{\max }$ denotes the maximum tension stress, $S_{\max }=\left(\sigma_{\max } / f_{t}\right)$, and $N$ denotes the loading cycles.

4.3. Prediction of Fatigue Life. The basic procedure for fatigue life prediction of the shield lining is as follows:

(a) Use ABAQUS to obtain the time-history of stress of the shield tunnel lining, at the speed of $80 \mathrm{~km} / \mathrm{h}$ of the train.

(b) Analyse the amplitude, average value, and the corresponding cyclic times for one period of the stress by the rain-flow counting method and then calculate the damage of the tunnel lining using the Miner damage theory and $S-N$ equation of the concrete.

(c) Make an estimation of the fatigue life for the shield lining based on the calculated damage above.

Numerical simulations show that the standard segment at the bottom of the shield tunnel lining ring has the highest 


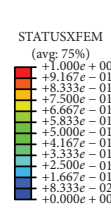

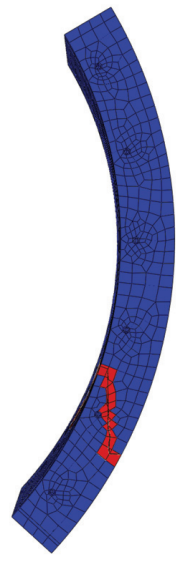

(a)
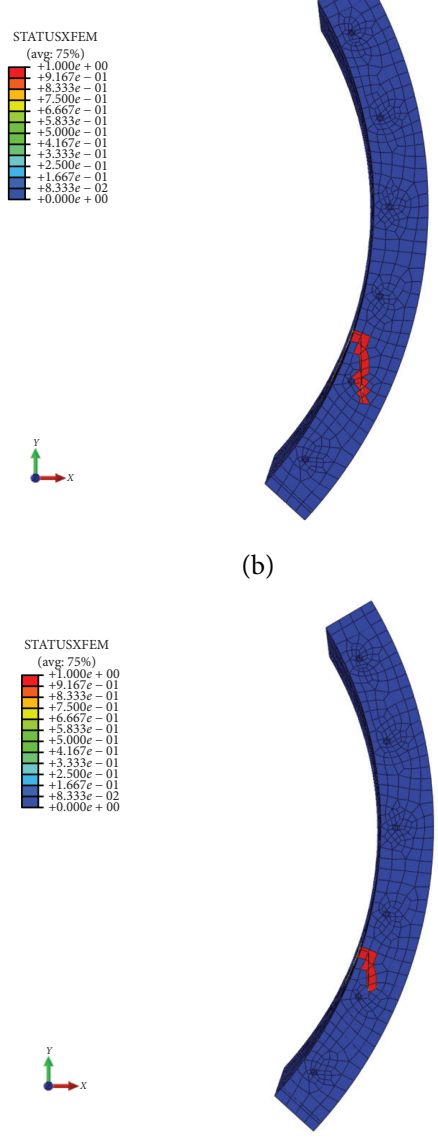

(b)

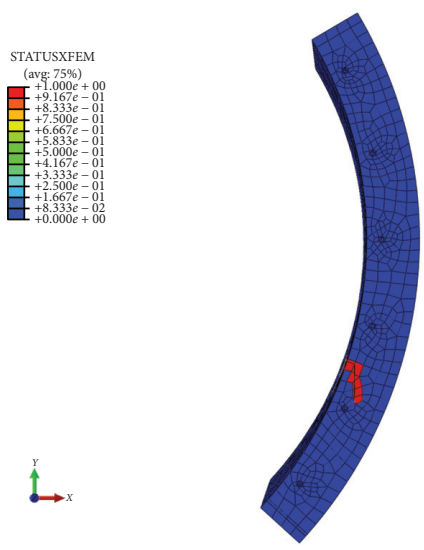

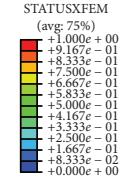

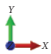

(c)

(d)

Figure 9: The final crack in the shied segment under different train axles: (a) $18 \mathrm{t}$; (b) $16 \mathrm{t}$; (c) $14 \mathrm{t}$; (d) $12 \mathrm{t}$.

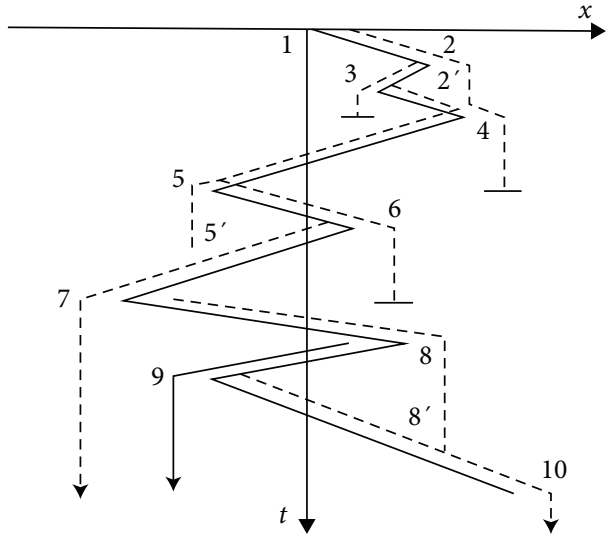

Figure 10: The schematic diagram for the rain-flow counting method.

stress level under the train vibration load. So, the standard segment at the bottom of the shield tunnel mainly determines the fatigue life of the structure. The time-history of stress of the standard segment at the bottom is illustrated in Figure 11.
The time-history curve of the stress in the standard segment at the bottom is analysed using the rain-flow counting method, and the amplitude, average value, and loading cycles of the stress are finally obtained, which is illustrated in Figure 12. 


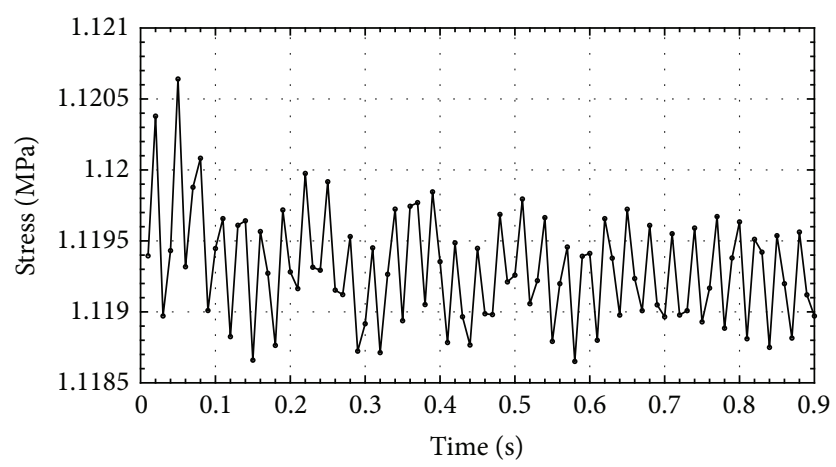

FIGURE 11: The time-history curve of the stress in standard segment at the bottom.

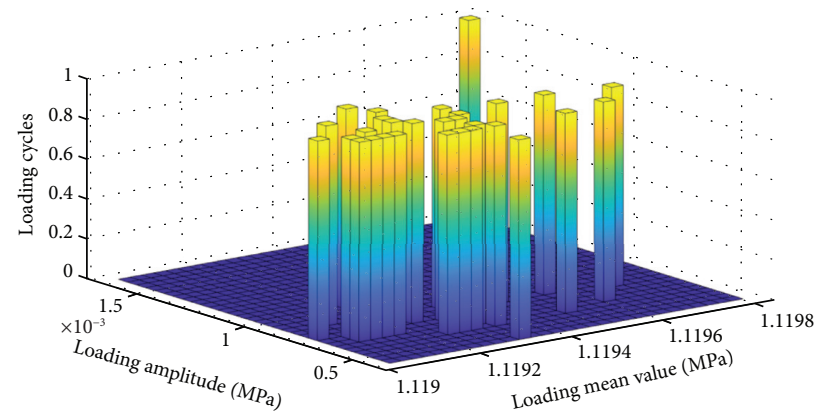

FIGURE 12: Stress analysis by the rain-flow counting method.

The damage to the shield tunnel segment caused by train vibration load for one time can be obtained by the above stress analysis, as in Figure 12, using the Miner damage theory and $S$ $N$ equation of the concrete, which is estimated as $2.42 \times 10^{-8}$, and its corresponding fatigue life $\lg N$ is about 7.62 .

The train of Nanjing Metro Line 5 departs 129 times a day and consists of 6 carriages. So, the cyclic time of the train vibration load for 100 years is about $N_{100}=6 \times 129 \times$ $365 \times 100=28251000$, and its corresponding $\lg N_{100}$ $=7.451<7.62$. Therefore, the shield tunnel lining structure of Nanjing Metro Line 5 can meet the demand of working for a hundred years under such working conditions.

\section{Conclusions}

In this paper, a three-dimensional numerical model of the shield tunnel lining structure is built to investigate the structure reaction and fatigue crack growth under train vibration load. Furthermore, damage of the shield segment caused by train vibration load is studied by employing the Miner damage theory and $S-N$ fatigue law of the concrete, and thus a rational fatigue life estimation for the concrete shield tunnel lining can be finally made. The following conclusions can be drawn:

(1) Crack propagation shows the overall same path under different train speeds, while the final crack lengths are a little different. The higher the train speed, the longer the final crack.
(2) Train axle has a larger influence than train speed on the crack propagation. The final crack under a heavier train axle is so long that it almost cuts through the shield segment, while the final crack under a lighter train axle is so short and it only develops to a local crack.

(3) The damage of the shield segment caused by train vibration load can be determined by the stress analysis using the rain-flow counting method, and the results show that the shield tunnel lining structure of Nanjing Metro Line 5 can meet the demand of working for a hundred years under the current working conditions.

\section{Data Availability}

The data used to support the findings of this study are included within the article.

\section{Conflicts of Interest}

The authors declare that they have no conflicts of interest.

\section{Acknowledgments}

This research was financially supported by the National Natural Science Foundation of China (grant no. 51808114) and Natural Science Foundation of Jiangsu Province (grant no. BK20170670). 


\section{References}

[1] H. H. Jenkins, J. E. Stephenson, G. A. Clayton, G. Morland, and D. Lyon, "The effect of track and vehicle parameters on wheel/rail vertical dynamic loads," Journal of Railway Engineering Society, vol. 3, no. 1, pp. 2-16, 1974.

[2] S. G. Newton and R. A. Clark, "An investigation into the dynamic effects on the track of $w$ on railway vehicles," Journal of Mechanical Engineering Science, vol. 21, no. 4, pp. 287-297, 1979.

[3] Y. B. Yang and H. H. Hung, "A 2.5D finite/infinite element approach for modelling visco-elastic bodies subjected to moving loads," International Journal for Numerical Methods in Engineering, vol. 51, no. 11, pp. 1317-1336, 2001.

[4] Y. B. Yang, H. H. Hung, and D. W. Chang, "Train-induced wave propagation in layered soils using finite/infinite element simulation," Soil Dynamics and Earthquake Engineering, vol. 23, no. 4, pp. 263-278, 2003.

[5] H. H. Hung, Y. B. Yang, and D. W. Chang, "Wave barriers for reduction of train-induced vibrations in soils," Journal of Geotechnical and Geoenvironmental Engineering, vol. 130, no. 12, pp. 1283-1291, 2004.

[6] X. Sheng, C. J. C. Jones, and D. J. Thompson, "Prediction of ground vibration from trains using the wavenumber finite and boundary element methods," Journal of Sound and Vibration, vol. 293, no. 3-5, pp. 575-586, 2006.

[7] X. Sheng, C. J. C. Jones, and D. J. Thompson, "Ground vibration generated by a harmonic load moving in a circular tunnel in a layered ground," Journal of Low Frequency Noise, Vibration and Active Control, vol. 22, no. 2, pp. 83-96, 2003.

[8] G. Degrande, D. Clouteau, R. Othman et al., "A numerical model for ground-borne vibrations from underground railway traffic based on a periodic finite element-boundary element formulation," Journal of Sound and Vibration, vol. 293, no. 3-5, pp. 645-666, 2006.

[9] J. A. Forrest and H. E. M. Hunt, "A three-dimensional tunnel model for calculation of train-induced ground vibration," Journal of Sound and Vibration, vol. 294, no. 4-5, pp. 678-705, 2006.

[10] J. A. Forrest and H. E. M. Hunt, "Ground vibration generated by trains in underground tunnels," Journal of Sound and Vibration, vol. 294, no. 4-5, pp. 706-736, 2006.

[11] V. A. Babeshko, M. G. Seleznev, T. N. Selezneva, and V. P. Sokolov, "On a method of studying steady-state oscillations of an elastic half-space containing a cavity," Journal of Applied Mathematics and Mechanics, vol. 47, no. 1, pp. 88-93, 1983.

[12] G. E. Kolodyazhnaya, M. G. Seleznev, and T. N. Selezneva, "Problem of a uniformly moving oscillating load acting on an elastic half-space containing a recessed cylindrical cavity," Mechanics of Solids, vol. 22, no. 6, pp. 83-87, 1987.

[13] W. Gardien and H. G. Stuit, "Modelling of soil vibrations from railway tunnels," Journal of Sound and Vibration, vol. 267, no. 3, pp. 605-619, 2003.

[14] A. J. B. Tadeu and E. Kausel, "Green's functions for two-anda-half-dimensional elastodynamic problems," Journal of Engineering Mechanics, vol. 126, no. 10, pp. 1093-1097, 2000.

[15] L. Gavrić, "Finite element computation of dispersion properties of thin-walled waveguides," Journal of Sound and Vibration, vol. 173, no. 1, pp. 113-124, 1994.

[16] A. A. Stamos and D. E. Beskos, "3-D seismic response analysis of long lined tunnels in half-space," Soil Dynamics and Earthquake Engineering, vol. 15, no. 2, pp. 111-118, 1996.
[17] J. E. Luco and H. L. Wong, "Seismic response of foundations embedded in a layered half-space," Earthquake Engineering \& Structural Dynamics, vol. 15, no. 2, pp. 233-247, 1987.

[18] C. G. Lai, A. Callerio, E. Faccioli, V. Morelli, and P. Romani, "Prediction of railway-induced ground vibrations in tunnels," Journal of Vibration and Acoustics, vol. 127, no. 5, pp. 503514, 2005.

[19] J. Huang, T. Yuan, L. Peng, J. Yu, and Z. Ding, "Model test on dynamic characteristics of invert and foundation soils of highspeed railway tunnel," Earthquake Engineering and Engineering Vibration, vol. 14, no. 3, pp. 549-559, 2015.

[20] D. P. Connolly, P. A. Costa, G. Kouroussis et al., "Large scale international testing of railway ground vibrations across Europe," Soil Dynamics and Earthquake Engineering, vol. 71, pp. 1-12, 2015.

[21] H. Yi, T. Qi, W. Qian et al., "Influence of long-term dynamic load induced by high-speed trains on the accumulative deformation of shallow buried tunnel linings," Tunnelling and Underground Space Technology, vol. 84, pp. 166-176, 2019.

[22] K. Wei, Z. Zhao, X. Du, H. Li, and P. Wang, "A theoretical study on the train-induced vibrations of a semi-active magneto-rheological steel-spring floating slab track," Construction and Building Materials, vol. 204, no. 20, pp. 703-715, 2019.

[23] L. G. Tian, L. T. Dong, S. Bhavanam, N. Phan, and S. N. Atluri, "Mixed-mode fracture \& non-planar fatigue analyses of cracked i-beams, using a 3D SGBEM-FEM alternating method," Theoretical and Applied Fracture Mechanics, vol. 74, pp. 188-199, 2014.

[24] L. G. Tian, L. T. Dong, N. Phan, N. Phan, and S. N. Atluri, "Non-planar mixed-mode growth of initially straight-fronted surface cracks, in cylindrical bars under tension, torsion and bending, using the symmetric Galerkin boundary element method-finite element method alternating method," Fatigue and Fracture of Engineering Materials and Structures, vol. 38, pp. 923-935, 2015.

[25] L. G. Tian, L. T. Dong, N. Phan, and S. N. Atluri, “Threedimensional SGBEM-FEM alternating method for analyzing fatigue-crack growth in and the life of attachment lugs," Journal of Engineering, vol. 141, Article ID 04014142, 2015.

[26] L. G. Tian and Z. L. Cheng, "Fracture and fatigue analyses of cracked structures using the iterative method," Geofluids, vol. 2021, Article ID 4434598, 12 pages, 2021.

[27] L. G. Tian and Z. L. Cheng, "A triangular plate bending element based on discrete Kirchhoff theory with simple explicit expression," Mathematics, vol. 9, no. 11, Article ID 1181, 2021.

[28] M. F. Kaplan, "Crack propagation and the fracture of concrete," ACI Journal, vol. 58, no. 5, pp. 591-610, 1960.

[29] A. Hillerborg, M. Modéer, and P. E. Petersson, "Analysis of crack formation and crack growth in concrete by means of fracture mechanics and finite elements," Cement and Concrete Research, vol. 6, pp. 773-778, 1976.

[30] T. Ralejs and T. Kutti, "Fatigue strength of plain, ordinary, and lightweight concrete," ACI Journal Proceedings, vol. 76, no. 5, pp. 635-652, 1979.

[31] Z. P. Bažant and B. H. Oh, "Crack band theory for fracture of concrete," Matériaux et construction, vol. 16, no. 3, pp. 155-177, 1983.

[32] J. Kim and Y. Kim, "Experimental study of the fatigue behavior of high strength concrete," Cement and Concrete Research, vol. 26, no. 10, pp. 1513-1523, 1996.

[33] S. P. Shah, "Determination of fracture parameters (KsIC and CTODc) of plain concrete using three-point bend tests," Materials and Structures, vol. 23, no. 6, pp. 457-460, 1990. 
[34] M. Kazemi, "Determination of fracture energy, process zone longth and brittleness number from size effect, with application to rock and conerete," International Journal of Fracture, vol. 44, no. 2, pp. 111-131, 1990.

[35] B. L. Karihaloo and P. Nallathambi, "Effective crack model for the determination of fracture toughness (KIce) of concrete," Engineering Fracture Mechanics, vol. 35, no. 4, pp. 637-645, 1990.

[36] Z. Wu, S. Xu, and J. Wang, "Fracture parameter of concrete based on the fictitious crack model," Journal of Hydraulic Engineering, vol. 30, no. 7, pp. 12-16, 1999.

[37] S. Xu and H. Reinhardt, "A simplified method for determining double-K fracture parameters for three-point bending tests," International Journal of Fracture, vol. 104, no. 2, pp. 181-209, 2000.

[38] L. G. Tian, Q. Zhang, X. Wang, and G. Zhang, “A prototype load test on fracture and damage properties of cracked shield tunnel lining segments," in Proceedings of the GeoShanghai 2018 International Conference: Tunnelling and Underground Construction, Springer, Shanghai, China, May 2018.

[39] L. G. Tian, X. Wang, and Z. L. Cheng, "Numerical study on the fracture properties of concrete shield tunnel lining segments," Geofluids, vol. 2021, Article ID 9975235, 11 pages, 2021.

[40] P. C. Paris and F. A. Erdogan, "A critical analysis of crack propagation laws," Journal of Basic Engineering, vol. 55, pp. 528-534, 1963.

[41] X. J. Lu, "Study on the fatigue fracture of concrete and its size effect," MS. thesis, Dalian University of Technology, Dalian, China, 2000.

[42] C. Amzallag, J. P. Gerey, J. L. Robert, and J. Bahuaud, "Standardization of the rainflow counting method for fatigue analysis," International Journal of Fatigue, vol. 16, no. 4, pp. 287-293, 1994. 